\title{
Investigating the quality-of-life scale in patients with placental adhesion disorder undergoing a cesarean hysterectomy and partial uterine resection
}

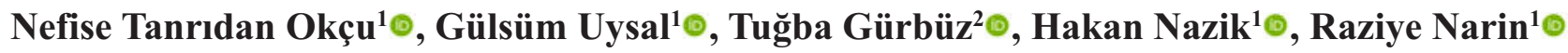 \\ ${ }^{1}$ Department of Obstetrics and Gynaecology, University of Health Sciences, Adana City Training and Research Hospital, Adana, Turkey; \\ ${ }^{2}$ Department of Obstetrics and Gynaecology, Medistate Kavactk Hospital, Istanbul, Turkey
}

\begin{abstract}
Objectives: This study aimed to investigate the postoperative quality-of-life of patients with placental adhesion disorder undergoing a cesarean hysterectomy and partial uterine resection.

Methods: This was a prospective study performed on 40 patients aged from 25 to 35 years. The subjects were divided into two groups based on whether the uterus was preserved or not following a cesarean hysterectomy and on partial uterine resection. The Turkish version of SF-36 Quality-of-life Scale consisting of 36 items and 8 subscales was applied to the patients.

Results: The participants had a mean age of $31.3 \pm 3.2$ years. The mean parity, number of cesarean sections and body mass index was $3.45,3.22$ and $29.1 \pm 2.9$, respectively. The mean physical function score was 83.4 \pm 11.61 in the cesarean hysterectomy group and $93.67 \pm 8.55$ in the partial uterine resection group. A significant difference was found between the cesarean hysterectomy and partial uterine resection groups in terms of their health-related quality-of-life $(p=0.005)$.

Conclusions: Patients who underwent partial uterine resection had improved health-related quality-of-life compared to patients who had a cesarean hysterectomy. Choosing uterus-preserving surgery in suitable patients by evaluating the degree of placental adhesion and adhesion size may have a positive effect on the quality-oflife after surgery.

Keywords: cesarean hysterectomy, partial uterine resection, placenta accreta, placental adhesion disorder, quality of life
\end{abstract}

$\mathrm{P}$ lacental adhesive disorder (PAD) is a serious complication of pregnancy occurring when the chorionic villi invades the myometrium [1]. Patients who are exposed to PAD have a scarred uterus. The two major risk factors of PAD are placenta praevia and a prior cesarean section, as well as curettage and previous uterine rupture, uterine artery embolization and conservative myomectomy [2]. The changing risk factors, such as the growing rate of cesarean delivery, have increased the rate of placenta accreta in the past forty years [3]. Depending on the extent of uterine invasion by trophoblastic tissue, PAD is divided into placenta increta, accreta and percreta lesions [4]. Placenta accreta can occur in cases of implantation of the chori- 
onic villi on the myometrium without involving the decidua. The placental villous tissues cause increta to invade the myometrium while the uterus has a percreta serosal layer in the adjacent organs caused by the chorionic villi [5]. The incidence of PAD has increased tenfold during the past fifty years despite its being regarded as a rare condition [6]. PAD is related to a high risk of emergency hysterectomy, massive post-partum hemorrhage (PPH), multiple blood transfusions, and maternal mortality and morbidity [7]. In the UK, this condition is the second most common cause of hemorrhage that results in peripartum hysterectomy [8].

PAD has traditionally been managed with different techniques such as a hysterectomy and a cesarean section causing hemorrhage and morbidity. Other therapeutic options, such as cesarean section avoiding the removal of the placenta combined with compression sutures, methotrexate, balloon tamponade and BLynch suture where the placenta remains in situ, have all been proposed in the past few decades $[9,10]$. One of the other conservative treatment strategies is reconstruction of the uterine wall and resection of the retained adherent placenta [11-13]. Moreover, the emphasis is more on improving the quality-of-life and the tendency to preserve the uterus. Therefore, in this study, the appropriateness of more conservative management of PAD surgery is discussed [14].

This study aimed to investigate the quality-of-life of PAD patients who had partial uterine resection and those who underwent cesarean hysterectomy to see if the partial uterine resection method positively affected the postoperative quality-of-life compared to cesarean hysterectomy.

\section{METHODS}

This study was a prospective one conducted in a tertiary hospital between January 2018 and December 2019 (Approval date:13.09.2017/Decision No:113). Postoperative Quality-of-life Scales were conducted and compared between patients who underwent cesarean hysterectomy or partial uterine excision due to PAD in our tertiary hospital between January 2013 and December 2018. The Quality-of-life Scale questionnaire was given to patients referred to the hospital for treatment at least 6 months after surgery and accepted to be included in the study. Those with psychiatric dis- orders, such as depression, anxiety disorder, chronic disease and multiple pregnancies were excluded from the study. Forty-six patients were contacted through electronic records. Six patients could not participate in the study for different reasons (living in a different city, diagnosis of depression, etc.). Therefore, forty patients aged from 25 to 35 years were included in the study. Written consents of the patients was obtained. The patients were divided into two groups depending on the operative methods: cesarean hysterectomy or partial uterine resection+bilateral tubal ligation. The SF-36 Quality-of-life Scale was developed for the first time by Stewart et al. [15]. Its Turkish validity was studied by Koçyiğit et al. [16]. The Turkish version of the SF-36 Quality-of-life Scale, consisting of 36 items, 8 subscales including physical role performance, general health, social function, energy, emotional role performance, physical function, pain and mental health, was applied to the patients. Scores related to the subscales vary from 0 to 100 , in which higher scores indicate a better level while lower scores indicate deteriorating health.

\section{Statistical Analysis}

The SPSS 18.0 statistical software package was used for data analysis. Continuous variables with normal data distribution were determined using mean \pm standard deviation, while variables with non-normal distribution were determined using median and lowest-highest values and categorical variables were determined with numbers and percentages. In univariate comparisons between the groups, t-test and variance analysis were applied to the groups independently of parametric tests based on the distribution of continuous variables, and the non-parametric Kruskal-Wallis test and the Mann-Whitney U-test were used. Categorical variables were compared using the Chi-square test. $P<0.05$ was considered to be significant.

\section{RESULTS}

Table 1 shows the demographic variables of the groups. No statistically significant difference was found between the groups in terms of gravidity, age, BMI, parity and number of cesarean sections (see Table 1). Based on the results obtained, no statistically significant difference was found between the groups 
Table 1. Descriptive statistics of demographic variables between groups

\begin{tabular}{lccccccc}
\hline & \multicolumn{3}{c}{$\begin{array}{c}\text { Cesarean hysterectomy } \\
(\mathbf{n}=\mathbf{2 5})\end{array}$} & \multicolumn{3}{c}{$\begin{array}{c}\text { Partial uterine resection } \\
(\mathbf{n}=\mathbf{1 5})\end{array}$} & p value \\
& Min & Max & Mean \pm SD & Min & Max & Mean \pm SD & \\
\hline Age (years) & 26 & 38 & $31.76 \pm 3.20$ & 25 & 36 & $30.73 \pm 3.12$ & 0.326 \\
\hline BMI $\left(\mathbf{k g} / \mathbf{m}^{2}\right)$ & 25 & 39.2 & $29.11 \pm 3.30$ & 25 & 33.6 & $29.08 \pm 2.36$ & 0.975 \\
\hline Gravidity & 3 & 7 & $5.2 \pm 1.04$ & 3 & 7 & $4.7 \pm 1.16$ & 0.166 \\
\hline Parity & 2 & 5 & $3.48 \pm 0.96$ & 2 & 5 & $3.40 \pm 0.73$ & 0.782 \\
\hline Number of living children & 2 & 5 & $3.44 \pm 1.00$ & 2 & 5 & $3.40 \pm 0.73$ & 0.893 \\
\hline Abortion & 0 & 3 & $0.72 \pm 0.79$ & 0 & 2 & $0.4 \pm 0.63$ & 0.190 \\
\hline Number of cesarean section & 2 & 5 & $3.2 \pm 0.76$ & 2 & 5 & $3.26 \pm 0.79$ & 0.813 \\
\hline
\end{tabular}

$\mathrm{Min}=$ minimum, $\mathrm{Max}=$ maximum, $\mathrm{SD}=$ standard deviation, $\mathrm{BMI}=$ Body Mass Index, $p<0.05$ statistically significant.

in terms of systemic disease, incision type and pathology results (see Table 2).

The research variables were studied according to physical function, physical problems due to restriction, physical pain scale, general health perception, Energy/Fatigue Scale, social function, emotional problems due to restriction and emotional well-being between the groups. The t-test of two independent populations was used to investigate the difference in these variables between the groups. The results are shown in Table 3.

The results obtained showed that the mean physi- cal function was statistically higher in the partial uterine resection group compared to the cesarean hysterectomy group $(p=0.005)$. The groups showed no statistically significant difference in other subscales ( $p$ $>0.05$ ) (Table 3).

\section{DISCUSSION}

This study showed a significant difference between the two cesarean hysterectomy and partial uterine resection groups. The mean physical function in

Table 2. The number and percent of the respondents stratified by systemic disease and incision type

\begin{tabular}{|c|c|c|c|c|c|}
\hline & \multicolumn{2}{|c|}{$\begin{array}{c}\text { Cesarean hysterectomy } \\
(\mathbf{n}=\mathbf{2 5})\end{array}$} & \multicolumn{2}{|c|}{$\begin{array}{l}\text { Partial uterine resection } \\
\qquad(\mathrm{n}=15)\end{array}$} & \multirow[t]{2}{*}{ p value } \\
\hline & Frequency & $\%$ & Frequency & $\%$ & \\
\hline Systemic disease & & & & & 0.707 \\
\hline 0 & 24 & 96.0 & 14 & 93.3 & \\
\hline 1 & 1 & 4.0 & 1 & 6.66 & \\
\hline Total & 25 & 100 & 15 & 100 & \\
\hline Incision type & & & & & 0.819 \\
\hline Midline & 21 & 84.0 & 13 & 86.66 & \\
\hline Phannenstiel & 4 & 16.0 & 2 & 13.3 & \\
\hline Total & 25 & 100 & 15 & & \\
\hline Pathology results & & & & & 0.078 \\
\hline Accreta & 16 & 64.0 & 14 & 93.3 & \\
\hline Increta & 7 & 28.0 & 1 & 6.66 & \\
\hline Percreta & 2 & 8.0 & 0 & 0 & \\
\hline
\end{tabular}


Table 3. Descriptive statistics of the research variables and - test for Equality of Means in two test groups

\begin{tabular}{|c|c|c|c|c|c|c|}
\hline & Group & $\mathbf{n}$ & Mean & SD & Std. Error Mean & $p$ value \\
\hline \multirow[t]{2}{*}{ Physical function } & Cesarean hysterectomy & 25 & 83.40 & 11.61 & 2.32 & $0.005^{*}$ \\
\hline & Partial uterine resection & 15 & 93.67 & 8.55 & 2.21 & \\
\hline \multirow{2}{*}{$\begin{array}{l}\text { Physical problems due to } \\
\text { restriction }\end{array}$} & Cesarean hysterectomy & 25 & 72.00 & 37.72 & 7.54 & 0.694 \\
\hline & Partial uterine resection & 15 & 76.67 & 33.36 & 8.61 & \\
\hline \multirow[t]{2}{*}{ Physical pain scale } & Cesarean hysterectomy & 25 & 69.30 & 20.74 & 4.15 & 0.282 \\
\hline & Partial uterine resection & 15 & 76.33 & 17.90 & 4.62 & \\
\hline \multirow[t]{2}{*}{ General health perception } & Cesarean hysterectomy & 25 & 66.20 & 20.52 & 4.10 & 0.906 \\
\hline & Partial uterine resection & 15 & 65.33 & 24.89 & 6.42 & \\
\hline \multirow[t]{2}{*}{ Energy/Fatigue scale } & Cesarean hysterectomy & 25 & 53.40 & 19.45 & 3.89 & 0.302 \\
\hline & Partial uterine resection & 15 & 60.33 & 21.67 & 5.59 & \\
\hline \multirow[t]{2}{*}{ Social function } & Cesarean hysterectomy & 25 & 79.00 & 20.64 & 4.12 & 0.383 \\
\hline & Partial uterine resection & 15 & 84.16 & 12.01 & 3.10 & \\
\hline \multirow{2}{*}{$\begin{array}{l}\text { Emotional problems due to } \\
\text { restriction }\end{array}$} & Cesarean hysterectomy & 25 & 76.00 & 32.66 & 6.53 & 0.702 \\
\hline & Partial uterine resection & 15 & 80.00 & 30.34 & 7.83 & \\
\hline \multirow[t]{2}{*}{ Emotional well-being } & Cesarean hysterectomy & 25 & 62.08 & 17.29 & 3.46 & 0.281 \\
\hline & Partial uterine resection & 15 & 68.13 & 16.36 & 4.22 & \\
\hline
\end{tabular}

$\mathrm{SD}=$ standard deviation, ${ }^{*} p<0.05$ statistically significant.

the partial uterine resection group was statistically higher than that in the cesarean hysterectomy group.

PAD is a life-threatening condition that occurs when the placental villi is abnormally adherent and results in a myometrium defect or an absence of myometrial tissue [17]. In our previous case series where the surgical technique and results of partial uterine resection were evaluated retrospectively, it was concluded that the local resection technique was an effective and safe method for treating anterior PAD [13]. Moreover, Acar et al. [18] showed that partial uterine resection was an alternative, acceptable and conservative management technique in the case of PAD. Also, Karaman et al. [12] found that an effective, fertility-preserving and safe approach was the local resection of the percreta site.

In our current study comparing the postoperative quality-of-life of patients with partial uterine resection and cesarean hysterectomy, it can be said that partial uterine resection positively affected the quality-of-life. This may be answered simply by sparing the patient uterine surgery, especially in a population where the uterus is one of the important organs for life and continuity of reproduction. On the other hand, the partial resection method may cause abnormal uterine bleeding or infection due to longer operating times and more sutures on the uterus.

While we expected a positive effect in patients spared uterine surgery, we wanted to consider and evaluate the real quality-of-life based upon fit and tested scales. In the quality-of-life scoring, the difference in physical function scores was significant between the two groups. The statistically significantly higher physical function score in the group spared uterine surgery suggested that organ-preserving surgery may have had a positive effect on the physical function scores of the patients where the problem was unknown. Shabana et al. [19], who reported a modified surgical approach, i.e. stepwise cesarean section, emphasized that conservative surgery may be a modern medical approach option. Our findings are in line with the opinion by Matsubara et al. [20] stating that retention of the uterus may improve women's qualityof-life and preserve their sexual identity, irrespective 
of fertility.

Su et al. [21] suggested the use of primary cesarean hysterectomy as the treatment of abnormal invasive placenta, but conservative treatment may be used in women with a strong desire for fertility. This is in line with results of the study by Cui et al. [22] who concluded that the implanted placenta remaining in situ should preferably be chosen for PAD patients with a desire for fertility and those undergoing termination of pregnancy in the second trimester. Tong et al. [23] concluded that it was feasible to have placental retention and uterine conservation in carefully selected cases, which can avoid the complications of a cesarean hysterectomy.

There is a consensus among experts on a planned preterm cesarean hysterectomy as the approach recommended before the 35th gestational week [24, 25]. On the other hand, several studies have discussed the conservative method in different case series and case reports, claiming that conservative management that leaves the placenta in situ causes harmful effects. A review of all the studies reported between January 1985 and May 2006 by Timmermans et al. [26] showed that $80 \%$ of the 60 cases could preserve the uteri. Kuppermann et al. [27] compared health-related quality-of-life scores for patients after hysterectomy and uterus-preserving surgery (for benign gynecologic surgery). They found more dramatic improvements in hysterectomy and concluded that women undergoing hysterectomy had a 6-month delay in improvement compared to the women undergoing uterus-preserving surgery who tended to show immediate improvement. However, the patients in this study consisted of benign conditions, not PAD or obstetrical reasons. Matsuzaki et al. [28] found that conservative management had serious complications leading to unplanned hysterectomies, were there was a reported success rate of $61.8 \%$ for those undergoing the conservative technique, which is not in line with our study that resulted in increased physical function with the conservative technique.

\section{Limitations}

Our study had some limitations. Firstly, the posterior placenta was not evaluated due to the technical limitations of the partial resection surgery method. Secondly, we could not evaluate the preoperative quality-of-life scales of the patients. As far as we know, this study is the first one to evaluate the quality-of-life functions after cesarean hysterectomy and partial resection surgery due to placental adhesion disorders.

\section{CONCLUSION}

It was concluded that the partial uterine resection group had a higher health-related quality-of-life than the cesarean hysterectomy group. Studies are needed with large patient groups in which patients with placental adhesive disorder would be appropriate for uterus-preserving surgery, the postoperative qualityof-life scales and even evaluating the sexual functions of patients selected for uterus-preserving surgery.

\section{Authors' Contribution}

Study Conception: NTO, GU, TG; Study Design: NTO, HN, RN; Supervision: NTO, GU, TG; Funding: N/A; Materials: NTO, GU, HN, RN; Data Collection and/or Processing: NTO, GU, TG, HN, RN; Statistical Analysis and/or Data Interpretation: NTO, GU, HN, RN; Literature Review: NTO, GU, TG; Manuscript Preparation: NTO, TG, HN and Critical Review: NTO, GU, RN.

\section{Conflict of interest}

The authors disclosed no conflict of interest during the preparation or publication of this manuscript.

\section{Financing}

The authors disclosed that they did not receive any grant during conduction or writing of this study.

\section{REFERENCES}

1. Srisajjakul S, Prapaisilp P, Bangchokdee S. MRI of placental adhesive disorder. Br J Radiol 2014;87:20140294.

2. Josephs SC. Obstetric and gynecologic emergencies: a review of indications and interventional techniques. Semin Intervent Radiol 2008;25:337-46.

3. Society of Gynecologic Oncology; American College of Obstetricians and Gynecologists and the Society for Maternal-Fetal Medicine, Cahill AG, Beigi R, Heine RP, Silver RM, Wax JR. Placenta Accreta Spectrum. Am J Obstet Gynecol 2018;219:B216.

4. Cuthbert F, Teixidor Vinas M, Whitby E. The MRI features of placental adhesion disorder-a pictorial review. Br J Radiol 2016;89:20160284. 
5. Dekan S, Linduska N. Normal and pathological placental development: MRI and pathology. In: Prayer D, ed. Fetal MRI. Berlin,Heidelberg: Springer Berlin Heidelberg; 2011:pp. 403-42. 6. Chantraine F, Blacher S, Berndt S, Palacios-Jaraquemada J, Sarioglu N, Nisolle M, et al. Abnormal vascular architecture at the placental-maternal interface in placenta increta. Am J Obstet Gynecol 2012;207:188.e1-9.

7. Eshkoli T, Weintraub AY, Sergienko R, Sheiner E. Placenta accreta: risk factors, perinatal outcomes, and consequences for subsequent births. Am J Obstet Gynecol. 2013;208:219.e1-7.

8. Knight M; UKOSS. Peripartum hysterectomy in the UK: management and outcomes of the associated haemorrhage. BJOG 2007;114:1380-7.

9. Kayem G, Davy C, Goffinet F, Thomas C, Clément D, Cabrol D. Conservative versus extirpative management in cases of placenta accreta. Obstet Gynecol 2004;104:531-6.

10. Eller AG, Porter TF, Soisson P, Silver RM. Optimal management strategies for placenta accreta. BJOG 2009;116:648-54.

11. Palacios Jaraquemada JM, Pesaresi M, Nassif JC, Hermosid S. Anterior placenta percreta: surgical approach, hemostasis and uterine repair. Acta Obstet Gynecol Scand 2004;83:738-44.

12. Karaman E, Kolusarı A, Çetin O, Çim N, Alkış İ, Yıldızhan $\mathrm{R}$, et al. Local resection may be a strong alternative to cesarean hysterectomy in conservative surgical management of placenta percreta: experiences from a tertiary hospital. J Matern Fetal Neonatal Med 2017;30:947-52.

13. Uysal G, Tanridan Okcu N, Eskimez E, Yılmaz Esra. Local resection for placenta accreta spectrum: a conservative uterus sparing technique for anterior placenta accreta. Eur Res J 2019;5:50-57.

14. Peng Q, Zhang W, Liu Y. Clinical application of stage operation in patients with placenta accreta after previous caesarean section. Medicine (Baltimore) 2018;97:e10842.

15. Stewart AL, Hays RD, Ware JE. The MOS Short-Form General Health Survey: reliability and validity in a patient population. Med Care 1988;26:724-35.

16. Koçyigit H, Aydemir O, Fisek G, Olmez N, Memis A. [The reliability and validity of the Turkish verison of Short form-36 (SF-36)]. İlaç ve Tedavi Dergisi 1999;12:102-6. [Article in Turkish]
17. Zhao X, Tao Y, Du Y, Zhao L, Liu C, Zhou Y, Wei P. The application of uterine wall local resection and reconstruction to preserve the uterus for the management of morbidly adherent placenta: case series. Taiwan J Obstet Gynecol 2018;57:276-82. 18. Acar H, Verit FF, Baydogan S, Cetin O, Kurdoglu M. Conservative treatment of a placenta accreta case: partial segmental uterine resection. Int J Womens Health Reproduct Sci 2016;4:845.

19. Shabana A, Fawzy M, Refaie W. Conservative management of placenta percreta: a stepwise approach. Arch Gynecol Obstet 2015;291:993-8.

20. Matsubara S. Comments on: segmental uterine wall resection for placenta accreta spectrum disorder: for what purpose? Rev Bras Ginecol Obstet 2018;40:652-3.

21. Su HW, Yi YC, Tseng JJ, Chen WC, Chen YF, Kung HF, et al. Maternal outcome after conservative management of abnormally invasive placenta. Taiwan J Obstet Gynecol 2017;56:3537.

22. Cui R, Li M, Lu J, Bai H, Zhang Z. Management strategies for patients with placenta accreta spectrum disorders who underwent pregnancy termination in the second trimester: a retrospective study. BMC Pregnancy Childbirth 2018;18:298.

23. Tong SY, Tay KH, Kwek YC. Conservative management of placenta accreta: review of three cases. Singapore Med J 2008;49:e156-9.

24. Committee on Obstetric Practice. Committee opinion no. 529: placenta accreta. Obstet Gynecol 2012;120:207-11.

25. Fox KA, Shamshirsaz AA, Carusi D, Secord AA, Lee P, Turan OM, et al. Conservative management of morbidly adherent placenta: expert review. Am J Obstet Gynecol 2015;213:755-60. 26. Timmermans S, van Hof AC, Duvekot JJ. Conservative management of abnormally invasive placentation. Obstet Gynecol Surv 2007;62:529-39.

27. Kuppermann M, Learman LA, Schembri M, Gregorich SE, Jackson RA, Jacoby A, et al. Contributions of hysterectomy and uterus-preserving surgery to health-related quality of life. Obstet Gynecol 2013;122:15-25.

28. Matsuzaki S, Yoshino K, Endo M, Kakigano A, Takiuchi T, Kimura T. Conservative management of placenta percreta. Int J Gynecol Obstet 2018;140:299-306. 